\title{
Editorial
}

\section{Geben Sie uns Feedback}

_ Vor anderthalb Jahren haben wir in ergopraxis ein neues Format integriert: den Refresher. Unsere Refresher sind Lernartikel, mit denen Sie Ihr Wissen auffrischen können. Zu Beginn jedes Artikels stehen Lernziele, am Ende zehn Fragen, um das Gelernte zu überprüfen. In dieser Ausgabe finden Sie den Refresher „Hilfseinrichtungen der Handmuskeln“ übrigens auf Seite 18.

_ Nun interessiert uns, ob Ihnen die Lernartikel weiterhelfen. Sind die Themen für Sie relevant? Wie hilfreich sind die Wissensfragen? Was können wir verbessern? Wir freuen uns, wenn Sie die Refresher bis zum 30.11.2014 beurteilen: http://bit.ly/Refresher_Umfrage.

_ Unter allen Teilnehmern verlosen wir zehn Buchpakete mit jeweils:

$>$ Ich werde Ergotherapeutin - Mit Lisa durch die Ausbildung

$>$ Das Taping-Selbsthilfe-Buch

$>$ Grafomotorik und Händigkeit

$>$ ERGODEM - Häusliche Ergotherapie bei Demenz

$>$ Ich liebe einen Asperger! Unsere Ehe, unsere Kinder - und das Asperger-Syndrom

_ In eigener Sache: Ich habe vor kurzem geheiratet und meinen alten Namen gegen einen neuen getauscht. Daher bin ich ab sofort unter maria.grupp@thieme.de erreichbar.

Herzliche Grüße

Ihre

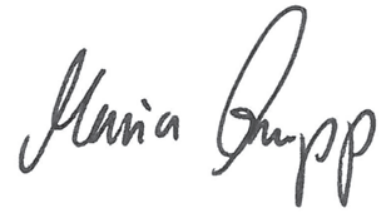

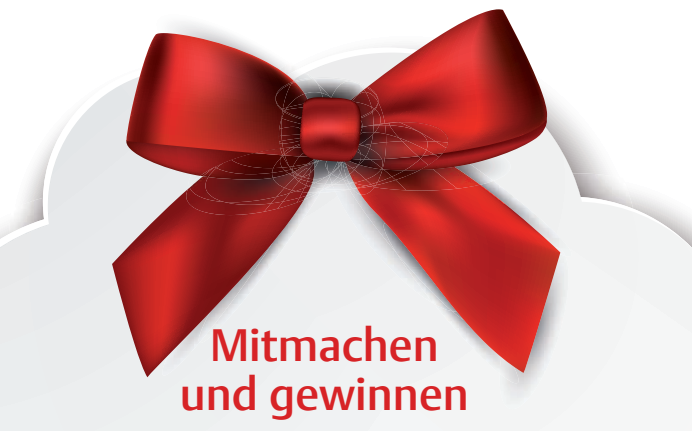

Wie gefallen Ihnen unsere „Refresher“? Nehmen Sie an unserer Umfrage teil: http://bit.ly/Refresher_Umfrage. Als Dankeschön für Ihr Feedback verlosen wir zehn Buchpakete im Wert von je 170,- Euro.

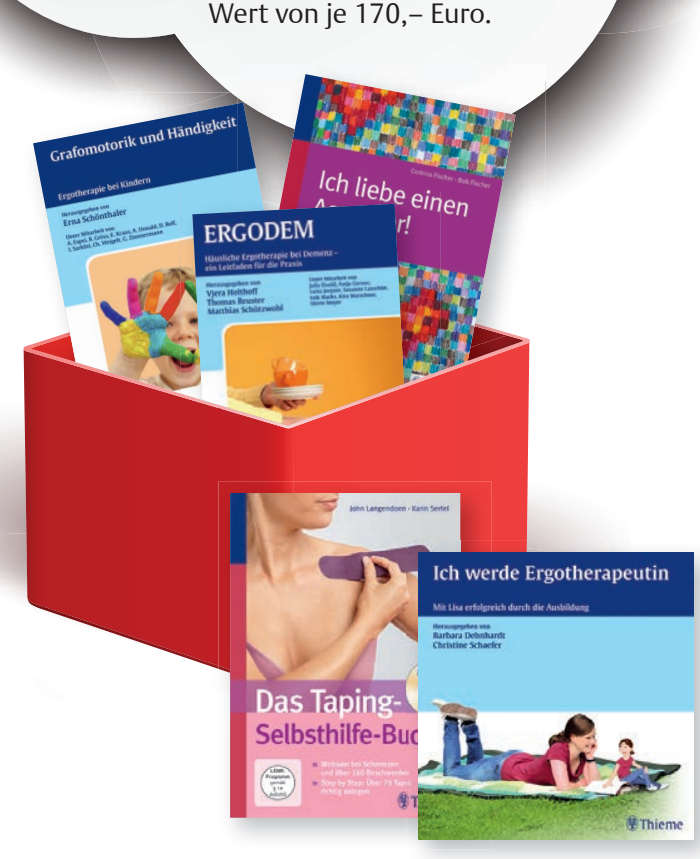

